\title{
EL CONSEJO GENERAL DEL PODER JUDICIAL: MARCO CONSTITUCIONAL
}

\author{
RICARDO PEDRO RON LATAS \\ Profesor Titular de Universidad - Universidade da Coruña \\ Magistrado suplente TSJ/Galicia \\ José FERnANDo LOUSADA AROCHENA \\ Magistrado especialista de lo social - TSJ/Galicia \\ Doctor en Derecho / Graduado Social
}

Fecha de recepción: 30.6.2016

Fecha de aceptación: 28.7.2016

\begin{abstract}
Resumen: El Consejo General del Poder Judicial en España se reconoce en el art. 122 de la CE como el órgano de gobierno de la judicatura, y se inscribe en la tendencia del constitucionalismo moderno dirigida a introducir una garantía institucional de la independencia judicial corporeizada en consejos de la magistratura que, a la vez que garantizan en sí mismos la independencia judicial, garantizan tendencialmente mejor la independencia judicial de los jueces individuales al detraer la gestión del estatuto judicial de las manos del Poder Ejecutivo. En este trabajo se desarrolla de manera crítica la configuración del mismo en nuestra Constitución.
\end{abstract}

Palabras clave: independencia judicial; Jueces y Magistrados; Consejo General del Poder Judicial; Constitución Española; Poder Judicial.

Abstract: The General Council of the Judiciary in Spain is being recognized in the art. 122 of the $\mathrm{CE}$ as the organ of government of the judiciary, and may be included in the tendency of the modern constitutionalism headed to enter an institutional guarantee of the judicial independence embodied in councils of Magistrates that, at the same time that they guarantee the judicial independence, they ensure the independence of the individual judges eliminating the management of the judicial statute of the hands of the Executive Power. In this work we develops, critical way, the configuration of the General Council of the Judiciary in our Constitution. 
Keywords: Judicial Independence; Judges and Magistrates; General Council of the Judiciary; Spanish Constitution; Judicial system.

SUMARIO: I. APROXIMACIÓN HERMENÉUTICA AL ARTÍCULO 122 DE LA CONSTITUCIÓN ESPAÑOLA. II. ¿HAY ANTECEDENTES EN EL DERECHO HISTÓRICO ESPAÑOL DEL CONSEJO GENERAL DEL PODER JUDICIAL? III. EL ÍTER PARLAMENTARIO DEL ARTÍCULO 122 DE LA CONSTITUCIÓN ESPAÑOLA. IV. LA NATURALEZA JURÍDICA DEL CONSEJO GENERAL DEL PODER JUDICIAL. V. LA JURISPRUDENCIA CONSTITUCIONAL. VI. A MODO DE CONCLUSIÓN: EL CONSEJO GENERAL DEL PODER JUDICIAL COMO GARANTE INSTITUCIONAL DE LA INDEPENDENCIA DEL PODER JUDICIAL.

\section{APROXIMACIÓN HERMENÉUTICA AL ARTÍCULO 122 DE LA CONSTITUCIÓN ESPAÑOLA}

La CE ha apostado seriamente por la independencia judicial. Su Título VI se denomina “del Poder Judicial". Y el artículo cabecera de ese Título VI establece, en su apartado 1, que "la justicia emana del pueblo y se administra en nombre del Rey por Jueces y Magistrados integrantes del poder judicial, independientes, inamovibles, responsables y sometidos únicamente al imperio de la ley". Bajo ese frontispicio, el artículo 122, apartados 2 y 3, de la CE instaura el CGPJ como una institución novedosa cuya razón de ser se explica, de un lado, en respuesta al déficit de independencia judicial real, más allá de las tan altisonantes como vacuas declaraciones legislativas, que caracterizó a nuestra historia constitucional a consecuencia de las potestades sobre la gestión del estatuto judicial que siempre había retenido el Poder Ejecutivo a través del Ministerio de Justicia, y, de otro lado, alineándose en la corriente originaria del constitucionalismo latino que, dentro de la evolución del Estado liberal de Derecho al Estado constitucional de Derecho, pretende más independencia judicial en sistemas de carrera judicial de modelo napoleónico y en democracias posteriores a regímenes corporativos donde la independencia judicial era más quimera que realidad. Corriente cristalizada en los consejos de la magistratura de las Constituciones francesas de $1946 \mathrm{y}$ de 1958, de la Constitución portuguesa de 1976, y, muy particularmente, de la Constitución italiana de 1947, que fue el modelo que más claramente inspiró a la $\mathrm{CE}^{1}$.

El artículo 122, apartados 2 y 3, de la CE, establece, en su apartado 2, que "el CGPJ es el órgano de gobierno del mismo (es decir, del Poder Judicial)", y que "la ley orgánica establecerá su estatuto y el régimen de incompatibilidades de sus miembros y sus funciones, en particular en materia de nombramientos, ascensos, inspección y régimen disciplinario", sobreentendiéndose que esa ley orgánica es a la que se refiere el apartado 1 -o sea la LOPJ-, y en el 3 que "el CGPJ estará integrado por el Presidente del TS, que lo presidirá, y por veinte miembros nombrados por el Rey por un periodo de

\footnotetext{
${ }^{1}$ Así se afirma en la página web del CGPJ: "En el constituyente español influyó la Constitución francesa de 1946 ... fue el precedente de los demás órganos de similar finalidad establecidos después en la Constitución italiana de 1947 ... y en la portuguesa de 1976 ... El modelo italiano fue importado por las Cortes Constituyentes en sus aspectos fundamentales, salvo por lo que se refiere a sus componentes que, en el caso español, quedó fijado en la Constitución".
} 
cinco años", y que "de estos, doce entre Jueces y Magistrados de todas las categorías judiciales, en los términos que establezca la ley orgánica; cuatro a propuesta del Congreso de los Diputados, y cuatro a propuesta del Senado, elegidos en ambos casos por mayoría de tres quintos de sus miembros, entre abogados y otros juristas, todos ellos de reconocida competencia y con más de quince años de ejercicio en su profesión".

No es mucho más lo que aporta la Constitución. Según el artículo 124 de la CE, el CGPJ será oído con carácter previo al nombramiento del Fiscal General del Estado. El artículo 159 de la CE le atribuye al CGPJ la propuesta para nombramiento de dos Magistrados del Tribunal Constitucional. Y, aunque no se dice explícitamente, siempre se ha entendido que, como le corresponde el nombramiento de todos los cargos judiciales -artículo 122.2 de la CE-, también nombra al Presidente del TS, que a su vez preside el CGPJ. Tales competencias directamente de designación o, en su caso, de audiencia, en el nombramiento de cargos tan relevantes como el Fiscal General del Estado, dos Magistrados del TC o el Presidente del TS y del propio CGPJ, son competencias trascendentales en el entramado constitucional de los poderes públicos.

Pero con ser trascendentales en dicho entramado constitucional, no son estas las competencias esenciales atribuidas en la CE al CGPJ, sino -de acuerdo con el artículo 122.2 de la CE- sus funciones "en materia de nombramientos, ascensos, inspección y régimen disciplinario", de ahí que, siendo esas materias las más sensibles del estatuto judicial en orden a la independencia de los jueces y magistrados, se está ratificando a través de la interpretación literal -que obliga a que esas funciones operen como un mínimo indisponible en los posteriores desarrollos legislativos- una idéntica conclusión a la anteriormente alcanzada con las perspectivas histórica y comparada: la competencia esencial del CGPJ se dirige a garantizar la independencia de los jueces y magistrados.

Tales competencias -tanto la esencial dirigida a garantizar la independencia de los jueces y magistrados como la de participación en el nombramiento de relevantes cargos estatales- nos sitúan ante un órgano que no es Poder Judicial, pues el CGPJ ni juzga ni hace ejecutar lo juzgado según se establece en el artículo 117.3 de la CE. Se trata, según la expresión del artículo 122.2 de la $\mathrm{CE}$, de un "órgano de gobierno" del Poder Judicial, aunque sin constituir órgano de representación los de los jueces, ni ejercer funciones políticas. Bajo estas premisas, el CGPJ está llamado constitucionalmente a intervenir en la política judicial, no solo como garante institucional de la independencia judicial, también como elemento activo en aras a mejorar el funcionamiento del Poder Judicial, aunque. Lo que resulta ser ya cuestionable -y sostenerlo sería interpretación excesiva de la expresión constitucionales que intervenga en el debate político más allá de la política judicial. Cuando lo ha hecho ha motivado la crítica de la doctrina científica y la opinión pública.

Sea como fuere, lo evidente es que el CGPJ no es integrante del Poder Judicial. La insistencia en esa apreciación es una afirmación muy reiterada así en la doctrina científica como en los propios discursos políticos. De esta afirmación se derivan múltiples consecuencias en el plano jurídico, de las cuales dos son muy evidentes. Una es que el CGPJ, al no ser Poder Judicial, no puede revisar las resoluciones de los órganos del Poder Judicial, ni siquiera indirectamente al socaire del ejercicio de sus facultades inspectoras o de régimen disciplinario; o sea las resoluciones del Poder Judicial no son recurribles ante el CGPJ. Y otra es que, como todo órgano de gobierno, 
las resoluciones del CGPJ pueden ser impugnadas ante el órgano del Poder Judicial que la ley establezca; o sea las resoluciones del CGPJ son recurribles ante el Poder Judicial.

Justamente esa no integración del CGPJ en el Poder Judicial, es lo que explica que la CE no extienda a sus vocales las garantías de inamovilidad atribuidas a los jueces y magistrados en el artículo 117.2 de la CE ("no podrán ser separados, suspendidos, trasladados, ni jubilados, sino por alguna de las causas y con las garantías previstas en la ley"), pues, según el artículo 122.2, será "la ley orgánica (la que) establecerá su estatuto (el del CGPJ) y el régimen de incompatibilidades de sus miembros", lo que, al margen de su tosca redacción, deja claro que el régimen de incompatibilidades de los vocales del CGPJ, y, en general, su estatuto, no es el de los jueces y magistrados, dejándose a la ley orgánica su determinación con gran amplitud, sin perjuicio, así las cosas, de que lo pueda tomar como referencia normativa, e incluso remitirse a él en aspectos puntuales.

En todo caso, la CE establece -y esta es una diferencia constitucional insalvable por vía del desarrollo de la ley orgánica entre el estatuto de los vocales y el estatuto judicial- un mandato temporal fijado en 5 años. La temporalidad del cargo de vocal se ha valorado como garantía de autonomía y ejercicio adecuado ${ }^{2}$. De autonomía porque se asegura, por esta vía indirecta, una mayor independencia de los vocales designados con respecto a quien los ha designado, tanto si son los jueces y magistrados -dada la duración ligeramente superior a la de 4 años habitual en cargos electivos-, como si son las Cortes Generales -cuyo mandato es justamente de 4 años-. Y de ejercicio adecuado porque un mandato intemporal podría derivar en la rutina burocrática que da la continuidad y en una perniciosa separación de los vocales respecto a la realidad judicial.

Como el artículo 122.3 de la CE establece un mandato temporal sin contemplar la posibilidad de la reelección, se ha venido considerando que, para una mejor efectividad de las finalidades de la temporalidad, los vocales salientes no pueden ser reelegidos, y así se ha plasmado en todos los desarrollos legislativos. Tal reelegibilidad sí se ha permitido en todos los desarrollos legislativos para el Presidente del TS aunque esa posibilidad nunca se haya llevado a la práctica-. Diferencia normativa que se apoya en una interpretación literal del artículo 122, apartado 3, de la CE en la medida en que los que son nombrados por el Rey por un periodo de cinco años son directamente los vocales del CGPJ, pero no el Presidente del TS. La justificación de la diferencia se ha encontrado en establecer una cierta garantía de continuidad en la actuación del CGPJ.

Quedando claro que el CGPJ, sin ser Poder Judicial, tiene como finalidad garantizar la independencia del Poder Judicial, lo que queda en el aire es el alcance de la

\footnotetext{
${ }^{2}$ Parecidamente, María Inmaculada Sánchez Barrios afirma que "las razones de esta temporalidad absoluta del cargo, de no más de cinco años, estribaban en la necesidad de cambiarse los miembros del CGPJ al ritmo de cambio de los electores, de los modernos problemas que se podían ir suscitando, de la más eficaz actividad de los consejeros ante el peligro de caer en la rutina burocrática que da la continuidad y, sobre todo, para limitarse en el tiempo el ejercicio de los poderes innatos al cargo ... incluso, más aún, esta limitación de un lustro podría ser una razón para los miembros de procedencia judicial, ya que si fuera mayor el tiempo cabría la posibilidad del olvido de las propias funciones jurisdiccionales y de que se desconectaran de las realidades vividas por el cuerpo electoral que continúa realizándolas ... con respecto a los vocales de procedencia parlamentaria, la temporalidad también es una garantía, y, en concreto, el que ese periodo - de cinco años- no coincida con la periodicidad de las elecciones generales -cuatro años-" (SANCHEZ BARRIOS, M.I., La elección de los miembros del Consejo General del Poder Judicial español y de sus homólogos europeos, Tirant lo Blanch, Valencia, 2009, p.136).
} 
autonomía necesaria para garantizar adecuadamente esa independencia del Poder Judicial pues existe "una relación dialéctica indisoluble entre la autonomía del Poder Judicial y la independencia del magistrado considerado singularmente" 3 . Y dentro del abierto marco constitucional caben múltiples modelos diferentes entre dos polos diferentes: el autogobierno pleno, es decir la atribución al CGPJ de todas las competencias en materia de justicia, lo que llevaría a la reducción hasta su mínima expresión, cuando no desaparición, del Ministerio de Justicia, y a la atribución al CGPJ de facultades de elaboración del propio presupuesto que presentaría a las Cortes Generales; o el autogobierno relativo u órgano autónomo de gobierno, es decir la atribución al CGPJ solo de ciertas funciones de ejercicio autónomo, que podrían recorrer desde el mínimo constitucionalmente establecido -nombramientos, ascensos, inspección y régimen disciplinario-, hasta las competencias del autogobierno pleno.

Tal cuestión guarda íntima relación con la composición del CGPJ, y, más concretamente, con la procedencia de los vocales que lo integran y con el sistema de designación de dichos vocales. Respecto a la procedencia de los vocales que lo integran, la $\mathrm{CE}$ es clara: hay 12 vocales judiciales y 8 vocales no judiciales. Una composición mixta que, salvo algunas críticas acaso excesivas de invasión del espacio judicial, se ha valorado positivamente al mantener una clara mayoría de miembros togados dentro de una "sana colaboración entre poderes (legislativo y judicial)" en una regla claramente inspirada en el sistema de "checks and balances". También se ha argumentado que "la participación de abogados, junto a los juristas, jueces y magistrados, en el CGPJ permite un foro de debate y de reflexión mucho más amplio y plural sobre las necesidades y flaquezas de la Administración de Justicia" 5 . Una composición mixta que -en lo que ahora nos interesa destacar- no impide, sin embargo, la idea de un autogobierno pleno.

Algunas precisiones adicionales en orden a la procedencia de los vocales se pueden deducir de la CE. En cuanto a los judiciales, la referencia a "todas las categorías judiciales" demuestra, de un lado, la preocupación por evitar que el CGPJ fuera copado por los Magistrados del TS (entonces casi todos nombrados por el Régimen franquista), y de otro lado, nos remite a la existencia de una Carrera Judicial, excluyendo así a aquellas personas que, ejerciendo funciones jurisdiccionales, no pertenecen a la Carrera Judicial. De este modo, no podrían ser designados dentro del cupo judicial los magistrados suplentes, los que sirven plazas de jueces como sustitutos, o los jueces de paz y sus sustitutos. Tampoco los Magistrados del Tribunal Constitucional. Más dudas se plantean con la Jurisdicción Militar, siendo alguna doctrina científica favorable a su

\footnotetext{
${ }^{3}$ María Luz Martínez Alarcón, quien explica que "a través del traspaso de competencias (del Ministerio de Justicia) al CGPJ ... (se ha pretendido) la autonomía del propio Poder Judicial ... (y) finalmente (esa) autonomía ... (pretende) como último objetivo ... la independencia personal de jueces y magistrados recogida en el artículo 117.1 de la CE y, en consecuencia, el respeto a ... la separación de poderes" (MARTÍNEZ ALARCÓN, M.L., La independencia judicial, Centro de Estudios Políticos y Constitucionales, Madrid, 2004, pp. 286-287).

${ }^{4}$ José Almagro Nosete, quien arropa esa afirmación de "sana colaboración" con la de que se evita "el carácter cerrado y pernicioso para la propia judicatura de un autogobierno exclusivo de los jueces", ALMAGRO NOSETE, J., "Poder Judicial y Tribunal de Garantías en la nueva Constitución", en AAVV Lecturas sobre la Constitución Española, UNED, Madrid, 1978, p. 297.

${ }^{5}$ María Ballester Cardell, quien añade que "se pretende que el pluralismo personal y profesional de sus miembros, desde los diferentes ámbitos del Derecho, contribuya a mejorar sensiblemente la eficacia y la eficiencia de las decisiones que se adoptan en beneficio el servicio público de la Justicia" (BALLESTER CARDELL, M., El Consejo General del Poder Judicial. Su función constitucional y legal, CGPJ, Madrid, 2007, pp. 168 a 170).
} 
inclusión dentro del cupo judicial, y, en cualquier caso, la inclusión es incuestionable cuando se trata de Magistrados de la Sala Quinta de lo Militar del Tribunal Supremo.

En cuanto a los vocales no judiciales, la CE exige "abogados y otros juristas, todos ellos de reconocida competencia y con más de quince años de ejercicio en su profesión". No basta, en consecuencia, con ostentar la Licenciatura de Derecho, lo que impide, por ejemplo, que un diputado u otro cargo político pueda ser designado como vocal si, aún siendo licenciado en Derecho, no ha ejercido efectivamente una profesión jurídica ${ }^{6}$. Tal circunstancia posibilita la implantación del autogobierno pleno, pues deja traslucir claramente la intención constitucional de instaurar un órgano que se maneje por criterios lógicos, objetivos y reflexivos, característicos del método jurídico, y, en consecuencia, alejados en la medida de lo posible de tendencias políticas coyunturales ${ }^{7}$.

Obsérvese que la norma únicamente se refiere, de entre las distintas profesiones jurídicas, a la Abogacía, sin contemplar expresamente -a pesar de que, como se verá, hubo algunos intentos de inclusión en el íter parlamentario de la Constitución- otras profesiones cuando menos tan cercanas a la Justicia como la Carrera Fiscal o el Secretariado Judicial, lo que ha generado ciertas críticas a la regulación constitucional, apaciguadas cuando, en la elección de los distintos CGPJ, se ha designado algún miembro de la Carrera Fiscal o del Secretariado Judicial, pero no ha sido así siempre, reabriéndose las críticas. Por otro lado, se ha planteado la cuestión de si entre el cupo de vocales no judiciales se pueden designar miembros de la Carrera Judicial, lo que no está literalmente excluido en la $\mathrm{CE}$, aunque ciertamente aparenta alejado de su espíritu.

Respecto al sistema de designación de los vocales, una composición elegida por los jueces y magistrados se compadece con la idea de autogobierno pleno mientras una composición elegida por quienes son ajenos al Poder Judicial nos acercan a la idea de órgano de gobierno autónomo. Al respecto de esta cuestión, la $\mathrm{CE}$, a diferencia de la cuestión de la procedencia de los vocales que lo integran, no se define en relación con los vocales judiciales, lo que contrasta claramente con la perfecta definición de quien elige a los no judiciales: cuatro a propuesta del Congreso de los Diputados, y cuatro a propuesta del Senado, elegidos en ambos casos por mayoría de 3/5 de sus miembros. Indefinición en relación con el sistema de designación de los vocales judiciales que

\footnotetext{
${ }^{6}$ Como dice María Inmaculada Sánchez Barrios, "la reconocida competencia solo se puede adquirir si realmente el ejercicio ha existido - por tanto, no se podrían computar los años que una persona ha sido, por ejemplo, diputado - lo que no quiere decir que no se puedan computar todos los años de ejercicio en varias profesiones o los años de desempeño de un cargo público cuando para el mismo fuera imprescindible la titulación de Licenciado en Derecho" (SANCHEZ BARRIOS, M.I., La elección de los miembros del Consejo General del Poder Judicial español y de sus homólogos europeos, Tirant lo Blanch, Valencia, 2009, pp. 40 y 41).

${ }^{7}$ Seguimos aquí las ideas de Juan Antonio Xiol Ríos / Juan José González Rivas / Jorge RodríguezZapata Pérez, quienes afirmaron que, "desde el punto de vista de la composición del CGPJ sobresale nuevamente su papel de órgano de garantía del adecuado funcionamiento del Poder Judicial que, si como órgano constitucional asume y eleva de rango político unas funciones tradicionalmente inmersas en el piélago de las funciones ejecutivas del Estado, desde el punto de vista de su composición postula un tratamiento reflexivo, metódico y jurídico de esas funciones", concluyendo en suma que "la Constitución, por tanto, presupone no solo que la función de gobierno del Poder Judicial va a ser tratada a un nivel distinto (el nivel propio de un órgano constitucional), sino también que va a serlo mediante un método distinto: el propio de un órgano de composición extensa e integrado por juristas inamovibles" (AA.VV., El Poder Judicial y su Consejo en el Estado social y democrático de Derecho, CGPJ, Madrid, 1986, p. 27).
} 
agudiza la indefinición entre el autogobierno pleno -que se compadece con su elección por y entre los jueces y magistrados- y la autonomía de gobierno -que no impediría su elección por mecanismos diferentes a la elección por y entre los jueces y magistrados-.

Si bien la aproximación hermenéutica al artículo 122, apartados 2 y 3, de la CE que hemos abordado en las páginas anteriores no permite alcanzar una solución segura a la cuestión de si se recoge un modelo de autogobierno pleno o un modelo de autonomía de gobierno, también es cierto que, aunque la $\mathrm{CE}$ solo dijo lo que dijo, la opinión política mayoritaria y la doctrina científica en la época tenían en mente la sustracción en mayor o menor medida de la gestión de la Justicia del ámbito del Poder Ejecutivo para dársela al CGPJ. Con ese consenso constitucional implícito se aprobó la Ley Orgánica 1/1980, de 10 de enero, que optó por un autogobierno pleno, y la LOTC no dudó en calificar al CGPJ como "órgano constitucional" -artículo 73 en relación con el 59-. Cuando ese consenso se rompió por los conflictos institucionales surgidos durante el mandato del I CGPJ (1980-1985), se volvió la vista a lo que dice la CE, y la CE dice solo lo que dice. $\mathrm{Y}$ es que la $\mathrm{CE}$ no acoge ningún modelo, sino que establece un marco.

\section{II. ¿HAY ANTECEDENTES EN EL DERECHO HISTÓRICO ESPAÑOL DEL CONSEJO GENERAL DEL PODER JUDICIAL?}

Obvia resulta la respuesta negativa aunque existieron algunas instituciones históricas que, por su denominación, por su composición o por sus funciones, presentaban coincidencias apreciables con el CGPJ. Probablemente, la institución histórica española que más se le parece es el Consejo Judicial de la Ley de 20 de diciembre de 1952 que, como fue la tónica general de nuestro derecho anterior a la CE de 1978, se quedó en una proclamación teórica de la independencia judicial, pues sus logros fueron limitados, por no decir directa y descarnadamente que fueron nulos. Asimismo se puede citar el Consejo Judicial del Real Decreto de 18 de mayo de 1917, pero sin llegar a entrar en vigor al ser derogado mediante otro Real Decreto de 18 de julio de 1917. Fue restablecido por un Real Decreto de 21 de junio de 1926 para ser nuevamente derogado por otro Decreto de 19 de mayo de 1931. Ya hemos dicho que ninguna de esas instituciones es un antecedente en sentido propio porque, más allá de ciertas coincidencias, ninguna se insertaba en un sistema democrático donde se garantizase realmente la independencia de los jueces y magistrados del Poder Judicial, y así se ha entendido por la doctrina más atinada ${ }^{8}$, e incluso en la página web del $\mathrm{CGPJ}^{9}$.

\footnotetext{
${ }^{8}$ Igualmente María Inmaculada Sánchez Barrios concluye que "ninguna de las reformas a que se ha hecho referencia es exponente de un auténtico precedente de nuestro actual CGPJ, aún a pesar de que algunos supusieron auténticos esfuerzos por erigirse en órganos de gobierno del Poder Judicial y garantes de su independencia. Pero el deseado autogobierno no podía ser real si no se daba una modificación del régimen político. El medio elemental para su nacimiento, de forma útil y auténtica, no es otro que la existencia de un sistema democrático. En plena transformación de la situación del país, se fueron haciendo notar aún con mayor intensidad las voces que denunciaban la excesiva intervención que había tenido el Gobierno en estas cuestiones y propugnaban la creación de un órgano nuevo que canalizara los deseos de un Poder Judicial independiente. El momento parece ser que llegó con la CE de 1978 y el CGPJ en ella previsto" (SANCHEZ BARRIOS, M.I., "Antecedentes del CGPJ en el Derecho español", Poder Judicial, número 46, 1997, P. 115).

${ }^{9}$ Efectivamente, en la página web del CGPJ se afirma lo siguiente: "En la Historia de España se encuentran algunos precedentes remotos de instituciones e intentos de crear un órgano que garantice el autogobierno del Poder Judicial, al menos parcialmente, pero ninguna alcanzó la misma naturaleza y
} 
Si hemos de buscar algún antecedente de auténtico gobierno judicial autónomo, se trataría de regulaciones nunca aplicadas o de algunos proyectos legislativos, pues han existido algunos intentos dirigidos a estatuir un auténtico gobierno judicial autónomo.

El primero de esos intentos fue, durante la I República, el inspirado por el Ministro Nicolás Salmerón, que se plasmó en el Decreto de 8 de mayo de 1973, donde se establecía que el acceso a la judicatura se realizase por propuesta individual y motivada del Tribunal Supremo, argumentando en su preámbulo "que es urgente emancipar por completo el Poder Judicial del Ejecutivo, no solo en el ejercicio de su autoridad, sino también en el nombramiento e investidura de sus representantes". Pero no se llegó a aplicar, tanto por las reticencias del propio TS que al parecer realizó gestiones confidenciales para que se le despojara de esas atribuciones, como por su corta vigencia, pues fue derogado el 14 de enero de 1874, dentro de un periodo muy convulso de la Historia de España. Francisco Beceña dice respecto de Salmerón que es "el ministro que más y más eficazmente laboró en pro de la independencia judicial"10.

Y el segundo de esos intentos fue el proyecto de Ángel Ossorio y Gallardo de 1929, en unas denominadas "Bases para la reorganización judicial" que, si bien ni eran bases normativas ni nunca se aprobaron, "contenían pronunciamientos muy interesantes y avanzados con respecto al Consejo Judicial que preveían y al Poder Judicial en general, llegando incluso a proponer la supresión del Ministerio de Justicia y Culto"11.

\section{EL ÍTER PARLAMENTARIO DEL ARTÍCULO 122 DE LA CONSTITUCIÓN ESPAÑOLA.}

Acaso debido a que las aproximaciones finalista, sistemática y literal al artículo 122, apartados 2 y 3, de la CE, unido a la ausencia de antecedentes históricos, no aportan demasiado a la configuración constitucional del CGPJ más que consagrarlo como una garantía institucional de la independencia judicial potenciada en la $\mathrm{CE}$, en los estudios doctrinales es referencia obligada el análisis de su íter parlamentario, aunque, sin con ello se busca una solución en el texto constitucional a las cuestiones planteadas con ocasión de los desarrollos legislativos acerca de la composición y del alcance de sus competencias, el esfuerzo será en vano. Si algo se deducirá de ese estudio será la ausencia de una solución cerrada a dichas cuestiones, con lo cual se confirma el carácter abierto de un marco constitucional que deja amplio margen de actuación al desarrollo legislativo. Pero no adelantemos nuestras conclusiones. El análisis del íter

\footnotetext{
finalidad que el CGPJ. En especial porque un órgano de este tipo solamente encuentra su auténtica razón de ser dentro de un régimen democrático, basado en la separación de poderes y en la tutela efectiva de los derechos fundamentales y libertades públicas. Entre esos antecedentes remotos destacan la Junta Central o Suprema (1849), la Junta Organizadora del Poder Judicial (1923) o el Consejo Judicial, creado por Real Decreto de 18 de mayo de 1917, aunque nunca llegó a funcionar al ser derogado en julio de ese mismo año. Se restableció en junio de 1926 para ser nuevamente derogado en mayo de 1931. Ninguno de estos ejemplos fue un precedente en sentido estricto. Tampoco lo fue el Consejo Judicial creado con la Ley de 20 de diciembre de 1952, y que operó hasta la implantación del régimen constitucional democrático".

${ }^{10}$ Citado por REQUERO IBÁÑEZ, J.L., El Gobierno Judicial y el Consejo General del Poder Judicial, Fundación para el análisis y los estudios sociales, Papeles de la Fundación, Madrid, 1996, p. 13.

${ }^{11}$ Utilizamos aquí las palabras de SANCHEZ BARRIOS, M.I., "Antecedentes del CGPJ en el Derecho español”, Poder Judicial, número 46, 1997,p. 112).
} 
parlamentario del artículo 122, apartados 2 y 3, de la CE lo realizaremos marcando hasta cuatro hitos.

(I) El Anteproyecto de Constitución, publicado el BOCG de 5.1.1978, establecía, en su artículo 112, que el CGPJ "es el órgano de gobierno de la Administración de Justicia - la ley orgánica establecerá su estatuto y funciones, en particular en materia de nombramientos, ascensos e inspección - sus miembros estarán sujetos al mismo régimen de incompatibilidades que el de los miembros del TC" -apartado 2-, y que "estará integrado por el presidente del TS, que lo presidirá, y por 20 miembros nombrados por el Rey, 12 a propuesta y en representación de las distintas categorías de la carrera judicial y 8 a propuesta del Congreso de los Diputados, entre juristas de reconocida competencia con más de 15 años de ejercicio en su profesión" -apartado 3-. No obstante, el Grupo UCD, al constatar la dificultad de un acuerdo en orden a la elección de vocales judiciales, formuló voto particular para reducir a 15 los vocales y para que los 10 judiciales se nombrasen "en los términos que establece la ley orgánica".

(II) Presentadas numerosas enmiendas al Anteproyecto de Constitución y, en concreto, a su artículo 112, la Ponencia elaboró un Informe donde se expresaba la aceptación o rechazo de cada enmienda con una concisa explicación, que, en lo que se refiere al artículo dedicado al CGPJ, además de modificar su numeración -paso del 112 al 114-, supuso, en lo que concierne al apartado 2, la modificación del enunciado donde dice el CGPJ "es el órgano de gobierno de la Administración de Justicia" para pasar a decir que "es el órgano de gobierno del mismo", es decir del Poder Judicial en consonancia con la denominación general del Título IV de la CE, "del Poder Judicial", que es de donde proviene la redacción definitiva del artículo 122, apartado 2, inciso inicial, de la $\mathrm{CE}$, mientras que, en lo que concierne al apartado 3 , hay cuatro cambios:

- En primer lugar, se elimina la expresión, referida a la elección de los vocales judiciales, "a propuesta y en representación de las distintas categorías de la carrera judicial", en línea con el voto particular del Grupo UCD al Anteproyecto de Constitución y con el apoyo de la mayoría de la representación de los Grupos UCD y Alianza Popular, y ello porque, aunque no era este su sentir propio, consideraron era la fórmula menos comprometida para llegar a un consenso, pues, sin excluir la elección de los vocales judiciales por los propios jueces, tampoco impide sea otro el método de designación, lo cual contentaría a una clase política siempre preocupada por el riesgo de corporativismo si los jueces asumieran un excesivo protagonismo a través de elecciones. Una delegación al legislador ordinario que sí pasará al texto constitucional definitivo.

- En segundo lugar, se modifica el número de vocales integrados en el CGPJ -de 20 vocales se pasa a 15 vocales, manteniéndose una proporción parecida entre los judiciales, 10, y los no judiciales, 5-. Un modificación no definitiva pues en el posterior íter se volvería a los 20 vocales distribuidos en 12 judiciales y 8 no judiciales, pero que es interesante destacar porque, al hilo de esa vuelta a los 20 vocales, se manifestó la opinión sobre elección de vocales judiciales mantenida por el Grupo Socialista - PSOE.

- En tercer lugar, el Proyecto presentado en el Informe de la Ponencia introduce en el tercer apartado del artículo 114 la exigencia de una mayoría cualificada (3/5 de los miembros del Congreso de los Diputados) para elegir a los cinco vocales dentro de la categoría de juristas de prestigio porque se entendió que, al exigir un mayor consenso en 
la designación del Congreso de los Diputados, se garantizaba la máxima independencia de los vocales elegidos entre juristas de reconocida competencia. La mayoría cualificada para designar estos vocales también acabará pasando al texto constitucional definitivo.

- En cuarto lugar, se introduce la duración del mandato de los vocales, que se establece en cinco años, un período ligeramente superior a la duración del mandato del Congreso de los Diputados con la intención de asegurar, por esta vía indirecta, una mayor independencia de los vocales designados. Una modificación que sí se mantendrá a lo largo del íter parlamentario y que al final acaba en el texto constitucional definitivo.

(III) Recibido el Informe de la Ponencia del Anteproyecto de Constitución por la Comisión de Asuntos Constitucionales y Libertades Públicas del Congreso de los Diputados, se elaboró, tras las oportunas discusiones, un Dictamen con un nuevo texto para su aprobación si procediere como Proyecto de Constitución por el Pleno del Congreso de los Diputados. El Dictamen de la Comisión de Asuntos Constitucionales y Libertades Públicas, además de cambiar la numeración del artículo -del 114 pasó al 116-, introdujo tres cambios en el CGPJ en comparación con el Informe de la Ponencia:

- Se introdujo entre las competencias constitucionales del CGPJ, la relativa al régimen disciplinario, porque se entendió era un elemento consustancial al concepto de gobierno judicial, una modificación que sí que pasará al texto constitucional definitivo.

- Se amplió nuevamente al número de 20 vocales que aparecía en el Anteproyecto de Constitución con la proporción de $3 / 5$ de vocales judiciales y de $2 / 5$ de vocales no judiciales. Tal ampliación fue consecuencia de una enmienda in voce del Portavoz del Grupo Parlamentario Socialista, quien la defendió afirmando que, con esa nueva ampliación, "iba a abrirse el colegio electoral, esta es al menos la interpretación de los socialistas, a todos los miembros, Jueces y Magistrados". Pero en el debate consiguiente a la enmienda no se avaló la interpretación dada por el Portavoz Socialista al sistema de elección de los vocales judiciales por los propios jueces y magistrados, sino solo la ampliación a 20 vocales, que pasará así al texto constitucional definitivo.

- Se especificaron ciertos datos relevantes en orden a los vocales a designar, como, en relación a los judiciales, que serán de todas las categorías judiciales -una precisión que había quedado eliminada cuando se eliminó el inciso "a propuesta y en representación de las distintas categorías de las carreras judiciales" contenido en el Anteproyecto de Constitución-, y, en cuanto a los no judiciales, se alude a la posibilidad de que sean nombrados abogados, aunque sin establecer una cuota, lo que se entiende como una admonición de que, en todo caso, exista algún abogado elegido entre vocales no judiciales. Modificaciones que también pasarán al texto definitivo de la Constitución.

El Proyecto de Constitución fue aprobado por el Pleno del Congreso de los Diputados sin que se hubiera realizado ningún cambio más que los recién detallados.

(IV) Con carácter general en relación con todo el Proyecto de Constitución aprobado por el Pleno del Congreso de los Diputados, el Senado no se limitó a refrendar lo que había hecho el Congreso de los Diputados, sino que los senadores presentaron muchas enmiendas, se generó una importante discusión y ello obligó a constituir una Comisión Mixta Congreso / Senado para sacar adelante el texto definitivo a someter a referéndum el 6.12.1978, y a su promulgación y su sanción por el Rey el 27.12.1978. En 
cuanto al artículo relativo al CGPJ, y tras su paso por la Comisión Mixta Congreso / Senado, pasó a ser el 122, definitivo. Se presentaron numerosas enmiendas, la mayoría dirigidas a garantizar la presencia de ciertos colectivos, y así una enmienda pretendía asegurar un vocal proveniente de la carrera fiscal, otra un vocal proveniente del cuerpo de secretarios, y otra un vocal abogado; también es destacable una del Grupo Progresistas y Socialistas Independientes para la elección de los doce vocales judiciales por todos los miembros de la carrera judicial; enmiendas que no fueron acogidas. La única sustancial admitida fue dar entrada en la designación de los vocales no judiciales al Senado, por considerar que la referencia exclusiva al Congreso de los Diputados suponía ir contra de la bicameralidad de las Cortes Generales. De este modo, el artículo 122, apartados 2 y 3, ha pasado al texto definitivo publicado en el BOE de 29.12.1979.

Si algo se puede sacar en conclusión después de examinar el íter parlamentario del artículo 122, apartados 2 y 3, de la CE, es que, en ese íter parlamentario, ya salieron a colación los dos más importantes problemas que se han planteado en relación con los desarrollos legislativos del CGPJ: la designación de sus miembros y el alcance de sus competencias. Lo que ocurre es que, en el debate constitucional, se pudieron alcanzar consensos a costa de dejar abiertas esas cuestiones, y en particular la cuestión de la composición del CGPJ. O sea -y como se adelantó ya desde el principio- el artículo 122, apartados 2 y 3 , de la CE no aporta una solución a dichas discusiones, con lo cual el marco constitucional es un marco abierto con un amplísimo margen al desarrollo legal, y ello deja un inmenso campo al debate institucional, político, mediático y doctrinal $^{12}$.

\section{LA NATURALEZA JURÍDICA DEL CONSEJO GENERAL DEL PODER JUDICIAL.}

Desde la entrada en vigor de la CE de 1978, es un tema recurrente en la doctrina científica española el de la naturaleza jurídica del CGPJ, en concreto, si es un órgano constitucional o si es un órgano de relevancia constitucional. La polémica es una traslación casi mimética de la polémica surgida en la doctrina italiana sobre la naturaleza jurídica del Consiglio Superiore della Magistratura, en donde unos defienden su naturaleza jurídica de órgano constitucional -posibilitando un reforzamiento de su posición institucional-, mientras otros la niegan -buscando su debilitamiento-. Una polémica doctrinal a contextualizar en un determinado entorno donde los jueces han asumido un gran protagonismo en la lucha contra la criminalidad mafiosa y contra la corrupción política. Ahora bien, ni las soluciones dadas en la doctrina italiana son trasladables al derecho español, ni la situación española es la misma que la italiana, de ahí que acaso la cuestión en España no tenga igual trascendencia que tiene en Italia.

\footnotetext{
${ }^{12}$ No en vano Manuel Terol Becerra ha dicho que "la sucinta regulación constitucional del Consejo, sin duda que calculada, considerando el grupo de enmiendas orientadas a configurar con cierto detalle la institución que fueron rechazadas durante el debate constituyente, supone casi una invitación a polemizar sobre su diseño legislativo definitivo - asunto este tanto más merecedor de atención cuanto ese parco tratamiento que concede al Consejo la Constitución, incluye, sin embargo, una habilitación expresa al legislador orgánico para que defina los perfiles del órgano apenas esbozado en ella" (TEROL BECERRA, M., "Veinticinco años del Consejo General del Poder Judicial", Revista Derecho Político, números 58/59, 2003/4, p. 644.
} 
Prescindiendo, en consecuencia, de la importación de soluciones alcanzadas para otros países, en España hay un argumento legal a favor de la consideración del CGPJ como órgano constitucional que se encuentra en la LOTC, en cuyo artículo 73, en relación con el 59, se legitima como "órgano constitucional" para interponer un conflicto a otros órganos constitucionales del Estado. Sin embargo, la naturaleza jurídica de una institución no se define por lo que la ley dice que es -invadiendo la legislación unas labores más propias de la doctrina-, sino por lo que efectivamente es. Y, en todo caso, esa calificación legal no permite concluir que el CGPJ deba satisfacer las características doctrinalmente asociadas a la calificación de órgano constitucional.

En los primeros años de la década de los ochenta, esa norma de la LOTC unida a la amplitud con la que se concibió al CGPJ en la Ley Orgánica 1/1980, de 10 de enero, avaló una postura doctrinal casi unánime a favor de atribuir al CGPJ el carácter de órgano constitucional. Así, se argumentó que "no cabe desconocer que el Consejo, como órgano de gobierno que es del Poder Judicial, tiene encomendada una función política de Estado que conlleva la selección de unos fines o logros políticos a cuya consecución atiende mediante una actividad que se concreta en actos generales o individuales"13. También se argumentó a favor que, "cuando se busca una correlación entre fines $\mathrm{o}$ directrices políticas constitucionales $\mathrm{y}$ órganos con funciones constitucionales al servicio de aquellos, se descubre que también desde esta otra perspectiva se ofrece el Consejo General como un verdadero órgano constitucional"14.

Una vez sustituida la Ley Orgánica 1/1980, de 10 de enero, por la Ley Orgánica 6/1985, de 1 de julio, del Poder Judicial, la doctrina científica empezó a cuestionar la calificación del CGPJ como órgano constitucional argumentando "la circunstancia de no hallarse realmente dotado de poderes políticos en sentido propio, de condiciones para ejercitar una influencia sobre el contenido sustancial de las normas primarias, mientras que son estas las que determinan su ámbito de actuación, que le sitúa en un rango subordinado y da a sus funciones un carácter más bien ejecutivo. En definitiva, el fundamento real del papel constitucional de un órgano no está tanto en el conjunto de las reglas que lo disciplinan, como el peso político que el mismo tiene en el sistema" ${ }^{\text {. }}$.

A pesar de esas críticas, un sector muy autorizado de la doctrina científica siguió considerando al CGPJ como un órgano constitucional porque, "cualquiera que sea el criterio determinante que se adopte para la delimitación de este escurridizo concepto, se trata de un órgano previsto y garantizado por la Constitución, supremo en su esfera de atribuciones (superiorem non recognoscens) y determinante, en cuanto protector de la independencia del Poder Judicial, de la forma de gobierno constitucional establecida"16.

Otro sector doctrinal más moderno niega el carácter de órgano constitucional del CGPJ, aunque tampoco lo asimila a un mero órgano administrativo dada la relevancia constitucional de sus funciones. De ahí se le catalogue como "órgano de relevancia

\footnotetext{
13 ALBACAR LOPEZ, J.L. "Naturaleza jurídica del Consejo General del Poder Judicial", en AAVV, Jornadas de estudio sobre el Consejo General del Poder Judicial, CGPJ, Madrid, 1983, p. 127.

${ }^{14}$ LEDESMA BARTRET, F., "Relaciones entre el Consejo General y el Poder Ejecutivo", en AAVV, Jornadas de estudio sobre el Consejo General del Poder Judicial, CGPJ, Madrid, 1983, p. 500.

15 ANDRESIBÁÑEZ, P., MOVILlA ÁlvAREZ, C., "El Poder Judicial", Teoría y realidad constitucional, $\mathrm{n}^{\circ} .8-9,2001-2002$, pp. 63 y 64.

16 DIEZ-PICAZO GIMÉNEZ, L., Régimen constitucional del Poder Judicial, Civitas, Madrid, 1991, página 133 .
} 
constitucional"17, o, de una manera algo más precisa, como "órgano de relevancia constitucional con funciones administrativas"18, o, con ciertos matices, como "órgano de relevancia constitucional de garantía" porque es "un órgano que, sin llegar a asumir un papel esencial -frente al elemento estructural al que sirve, cual es la independencia judicial- en la organización de poderes del Estado, actúa en beneficio de la misma"19.

Hecha esta aproximación general a las distintas opiniones doctrinales, debemos proceder a una disección en detalle de los argumentos y contraargumentos en orden a la consideración como órgano constitucional del CGPJ. Al respecto, los defensores de esa consideración construyen sus argumentos sobre cuatro ideas fuerza: es el órgano superior en el ámbito de su competencia; es un órgano esencial en un sistema constitucional; sus funciones garantizan el sistema constitucional; sus decisiones ostentan relevancia política. Los detractores de esa consideración critican esas ideas fuerza, lo cual les lleva a considerar se trata de un órgano con relevancia constitucional.

(1) ¿Es el CGPJ el órgano superior en el ámbito de su competencia? A favor de una solución afirmativa se argumenta que el órgano de gobierno ostenta competencias plenas sin someterse a jerarquía, lo cual supone que se sitúa "en el vértice del Poder Judicial, desvinculando, así a este último de toda dependencia de cualquier otro órgano de los restantes poderes del Poder Judicial"20. Tal argumentación es parcialmente incorrecta en cuanto a sus premisas -competencias plenas y no sumisión a jerarquía-, y totalmente incorrecta en cuanto a su conclusión -la de que se encuentra en el vértice del Poder Judicial-, aunque sí resultaría posible asumir dicha conclusión si la refiriésemos exclusivamente a los órganos con competencias gubernativas dentro del Poder Judicial.

De un lado, la CE no le garantiza al CGPJ competencias plenas en materia de justicia, y legalmente siempre se le ha reconocido la gestión del personal no jurisdicente y medios materiales al Ministerio de Justicia o, en su caso, a las CCAA. Ahora bien, el CGPJ sí ostenta competencias plenas en la gestión del estatuto judicial -que es, precisamente, la materia más sensible en orden a garantizar la independencia judicial-.

De otro lado, el CGPJ está sometido, como cualquier Administración Pública artículo 106 de la CE-, al control judicial, y en concreto sus actos son impugnables ante el Contencioso administrativo. Pero incluso el Parlamento como paradigmático órgano constitucional, se somete a la fiscalización del Tribunal Constitucional a través de cuestiones de constitucionalidad o recursos de amparo, sin por ello perder tal naturaleza.

\footnotetext{
${ }^{17}$ María Luz Martínez Alarcón, pues, "por el simple hecho de venir recogido en la Constitución Española", se encuentra protegido "frente a cualquier intento de modificarlo, o suprimirlo, extraño al procedimiento de reforma que ella misma contempla" (MARTíNEZ ALARCÓN, M.L., La independencia judicial, Centro de Estudios Políticos y Constitucionales, Madrid, 2004, p. 288).

${ }^{18}$ FERNÁNDEZ-MIRANDA CAMPOAMOR, C., "El Consejo General del Poder Judicial. De la Ley Orgánica 1/1980, de 10 de enero, a la Ley Orgánica 6/1985, de 29 de julio", Revista de Derecho Político, número 38, 1993, p. 52.

${ }^{19}$ BALLESTER CARDELL, M., El Consejo General del Poder Judicial. Su función constitucional y legal, CGPJ, Madrid, 2007, p. 164.

${ }^{20}$ Según Biscaretti di Ruffia, citado por BALLESTER CARDELL, M., El Consejo General del Poder Judicial. Su función constitucional y legal, CGPJ, Madrid, 2007, p. 135.
} 
La que sí es totalmente incorrecta es la conclusión de que el CGPJ se sitúa en el vértice del Poder Judicial, simplemente porque el CGPJ no es Poder Judicial, en cuanto que el CGPJ no se compone exclusivamente de jueces y magistrados, como el Poder Judicial -artículo 117.1 de la CE-, ni se limitan sus funciones a juzgar y hacer ejecutar lo juzgado, como el Poder Judicial -artículo 117.3 de la CE-. Ahora bien, el CGPJ sí se sitúa en el vértice de los órganos con competencias gubernativas dentro del Poder Judicial (los Presidentes y las Salas de Gobierno de los Tribunales Superiores de Justicia, los Presidentes de las Audiencias Provinciales y los Jueces Decanos), con lo cual es vértice de una función estatal asumida por órganos insertos en el Poder Judicial.

(2) ¿Es el CGPJ un órgano esencial en un sistema constitucional? A favor de una solución afirmativa se argumenta que el órgano autónomo de gobierno judicial garantiza la independencia judicial sin la cual no hay Estado de Derecho. Pero también es cierto que existen sistemas constitucionales en los cuales no existe un órgano autónomo de gobierno judicial sin que se confundan los poderes o se vulnere la independencia judicial -como Alemania o el Reino Unido-. Y también es cierto que la existencia de un órgano de gobierno judicial solo es garantía efectiva de la independencia judicial si, por su composición y por sus funciones, se instaura un órgano con real y efectiva autonomía. Con lo cual no es equivalente la ecuación órgano de gobierno judicial e independencia judicial, pues puede haber aquel sin esta, de igual modo que puede haber esta sin aquel.

(3) ¿Garantizan el sistema constitucional las funciones del CGPJ? A favor de una solución afirmativa se argumenta que, siendo la función del Poder Judicial esencial en el Estado de Derecho, la del CGPJ también lo es en la medida que busca garantizar la independencia judicial. Pero se le puede dar la vuelta a la afirmación diciendo que, aunque el CGPJ busca garantizar la independencia judicial, es el Poder Judicial el que ejerce una función esencial para el Estado de Derecho. De este modo, se entra en una argumentación en un bucle infinito, que no conduce nunca a ninguna conclusión sólida.

(4) ¿Ostentan relevancia política las decisiones del CGPJ? A favor de una solución afirmativa se argumenta que el CGPJ tienen amplias competencias, no solo en materia gubernativa, también en otros ámbitos -informe de leyes o en relación con la política judicial, designación de miembros del TC-. Pero, fuera de sus competencias en la materia gubernativa -que ciertamente son plenas-, en los demás ámbitos -a salvo la designación de miembros del TC- sus competencias son limitadas -informe o audiencia, ergo su influencia real en las decisiones de relevancia política no resulta muy elevada.

Todas estas argumentaciones demuestran la dificultad de llegar a una conclusión definitiva que convenza a toda la doctrina. A ello le unimos que, cuando abordó la cuestión de la naturaleza jurídica del CGPJ, el TC, sin haber negado sea un órgano constitucional, ha rechazado extraer las consecuencias que la doctrina anuda al concepto de órgano constitucional. Basta con leer el F.J. $11^{\circ}$ de la STC 108/1986, de 29 de julio: "Que una autorizada opinión doctrinal entienda que los órganos constitucionales, entre los que se incluye al Consejo, deban venir regulados en sus elementos esenciales, entre los que se incluiría la forma de designación de sus componentes, por la propia Constitución, no implica que del texto constitucional deban deducirse forzosamente todos estos elementos, cuando basta su simple lectura para comprobar que no regula algunos de ellos. Podrá decirse, en este caso, que la Constitución adolece de un fallo técnico, o que la doctrina citada no es aplicable en ese supuesto, o darse cualquier otra 
explicación; pero lo que no cabe es integrar un texto constitucional con una opinión doctrinal, por respetable que esta sea, haciendo decir a aquel lo que evidentemente no dice; ni semejante doctrina ha sido nunca expresada por este Tribunal Constitucional".

Si esto es así como lo expresa la jurisprudencia constitucional, la única conclusión final factible, dentro de una sensación de cierto agotamiento a la vista de la imposibilidad de llegar a soluciones doctrinalmente incuestionables, es la de que, con independencia de su calificación o no como órgano constitucional, al CGPJ no se le pueden asignar adherentes doctrinales más allá de lo establecido en la CE o en su desarrollo a través de la LOPJ. Por ello -y a consecuencia de ese agotamiento- alguna doctrina más moderna ha llegado a afirmar, de una manera ecléctica y a nuestro juicio compartible, que, en atención a los artículos 73 y 59 de la LOTC, al CGPJ "ha de tenérsele, ciertamente, por órgano constitucional (aunque) eso no significa, sin embargo, que posea los rasgos que doctrinalmente se han atribuido a los de esta naturaleza" 21 .

\section{LA JURISPRUDENCIA CONSTITUCIONAL.}

La trascendental cuestión de si el artículo 122, apartados 2 y 3, de la CE respondía a un sistema de autogobierno pleno o un sistema de autogobierno limitado fue especialmente cruenta durante el mandato del I CGPJ, dado que este acogió los postulados del autogobierno pleno, provocando un conflicto institucional y una reacción por parte del Gobierno del PSOE que desembocó en una restrictiva Ley Orgánica 6/1985, de 1 de julio, del Poder Judicial, tanto en orden a limitar las competencias del CGPJ como en orden al sistema de elección de los vocales del CGPJ. Y, como esta fue recurrida ante el TC, de un lado, por el propio CGPJ a través del conflicto entre órganos constitucionales, $y$, de otro lado, por parlamentarios de Alianza Popular a través de un recurso de inconstitucionalidad, existe una jurisprudencia que aborda la cuestión: la STC 45/1986, de 17 de abril, que resolvió el conflicto entre órganos constitucionales, y la STC 108/1986, de 29 de julio, que resolvió el citado recurso de inconstitucionalidad.

De las argumentaciones jurídicas de la STC 45/1986 y de la STC 108/1986 se pueden extraer las siguientes conclusiones en relación con la cuestión del autogobierno pleno / autogobierno relativo, y, en general, en relación con la autonomía del CGPJ:

1a. El CGPJ no es un órgano representativo de los jueces y magistrados integrantes del Poder Judicial. Para llegar a esa conclusión, la STC 45/1986 -en su F.J. $5^{\circ}$ - descarta uno a uno todos los argumentos utilizados por el CGPJ. Comienza afirmando que "no hay nada ni en la Constitución, ni en la anterior Ley Orgánica del CGPJ, ni en la actual LOPJ, que autorice a sostener la pretensión de representación procesal por el CGPJ, como tal". Más allá de esa constatación formal, el TC argumenta que, "al configurarse constitucionalmente como su órgano de gobierno, no podría ser, ni siquiera a efectos procesales, representante del Poder Judicial, pues ello estaría en contradicción con el principio constitucional de independencia de Jueces y Magistrados

\footnotetext{
${ }^{21}$ Opinión sustentada por MURILLO DE LA CUEVA, P.L., "La posición constitucional del Consejo General del Poder Judicial y sus relaciones con los órganos constitucionales", en AAVV, El Gobierno del Poder Judicial en el Estado autonómico: Evolución y perspectivas de reforma", Marcial Pons, Madrid, 2013, p. 50.
} 
(artículo 117.1 CE)". Además se rechaza "la alegación de que, de no acogerse el conflicto, quedarían privadas de garantía constitucional las atribuciones de Jueces y Magistrados frente a los atentados de que las mismas pudieran ser objeto por un órgano constitucional, pues no cabe confundir la garantía constitucional de un órgano o de una institución con el reconocimiento de legitimación en el proceso constitucional a tal órgano o institución para la actualización de esa misma garantía”. Por último, se afirma que "la Constitución ofrece un sistema de garantías suficientes como para depurar a su través las extralimitaciones en las que pudiera incurrir un órgano constitucional, también, por lo tanto, el Congreso o el Senado, en menoscabo de los órganos integrados en el Poder Judicial. La existencia de un recurso de inconstitucionalidad pendiente contra el sistema de elección de los miembros del CGPJ es una buena muestra de ello".

$2^{\mathrm{a}}$. El CGPJ no es expresión del autogobierno de los jueces y magistrados. Para llegar a esa conclusión, la STC 108/1986 empieza recordando las premisas normativas relativas a la independencia judicial -en su F.J. $6^{\circ}{ }_{-}^{22}$ y al órgano de gobierno judicial en su F.J. $7^{\circ}{ }^{23}$. Y, después de ello, la STC 108/1986 -en su F.J. $8^{\circ}$ - afirma que lo que es "el meollo de las alegaciones de los recurrentes", es decir, "que la independencia judicial y la existencia constitucional del Consejo comportan el reconocimiento por la Constitución de una autonomía de la Judicatura, entendida como conjunto de todos los Magistrados y Jueces de carrera, y, en consecuencia, la facultad de autogobierno de ese

\footnotetext{
22 "La independencia del Poder Judicial no hay duda de que constituye una pieza esencial de nuestro ordenamiento como del de todo Estado de Derecho, y la misma Constitución lo pone gráficamente de relieve al hablar expresamente del Poder Judicial, mientras que tal calificativo no aparece al tratar de los demás poderes tradicionales del Estado, como son el Legislativo y el Ejecutivo. El Poder Judicial consiste en la potestad de ejercer la jurisdicción, y su independencia se predica de todos y cada uno de los jueces en cuanto ejercen tal función, quienes precisamente integran el poder judicial o son miembros de él porque son los encargados de ejercerla. Así resulta claramente del artículo 117.1 de la CE, con que se abre el Título VI de la misma dedicado al Poder Judicial: La justicia emana del pueblo y se administra en nombre del Rey por Jueces y Magistrados integrantes del Poder Judicial, independientes, inamovibles, responsables y sometidos únicamente al imperio de la Ley. Naturalmente, la independencia judicial (es decir, la de cada Juez o Tribunal en el ejercicio de su jurisdicción) debe ser respetada tanto en el interior de la organización judicial (artículo 12 de la LOPJ) como por todos (artículo 13 de la misma Ley). La misma Constitución prevé diversas garantías para asegurar esa independencia. En primer término, la inamovilidad, que es su garantía esencial (artículo 117.2); pero también la reserva de ley orgánica para determinar la constitución, funcionamiento y gobierno de los Juzgados y Tribunales, así como el estatuto jurídico de Jueces y Magistrados (artículo 122.1), y su régimen de incompatibilidades (artículo 127.2)".

23 "La concepción expuesta de la independencia del Poder Judicial es compartida, en sus líneas generales, por todos los países de nuestra área jurídico-política. Pero algunos de esos países han incorporado a sus Constituciones garantías específicas a fin de que esa independencia no se vea perturbada por medios más indirectos o sutiles. Tal fue el caso de Italia en su Constitución de 1948 (sic, es de 1947), o de Portugal en la suya de 1976, y siguiendo en parte su ejemplo, el de España en su vigente Constitución. Esta última, en su artículo 122.2, prevé la existencia de un CGPJ como órgano de gobierno del mismo que será regulado por ley orgánica, la cual establecerá su estatuto y el régimen de incompatibilidades de sus miembros y sus funciones, en particular en materia de nombramientos, ascensos, inspección y régimen disciplinario. Así, las funciones que obligadamente ha de asumir el Consejo son aquellas que más pueden servir al Gobierno para intentar influir sobre los Tribunales: de un lado, el posible favorecimiento de algunos Jueces por medio de nombramientos y ascensos; de otra parte, las eventuales molestias y perjuicios que podrían sufrir con la inspección y la imposición de sanciones. La finalidad del Consejo es, pues, privar al Gobierno de esas funciones y transferirlas a un órgano autónomo y separado. Es, desde luego, una solución posible en un Estado de Derecho, aunque (ello) ... no es su consecuencia necesaria ni se encuentra, al menos con relevancia constitucional, en la mayoría de los ordenamientos jurídicos actuales".
} 
conjunto de Magistrados y Jueces cuyo órgano sería precisamente el Consejo", ni se reconoce en la $\mathrm{CE}^{24}$, ni se deriva de la existencia, composición y funciones del $\mathrm{CGPJ}^{25}$.

Asimismo aborda la STC 108/1986 la cuestión de la elección de los vocales judiciales, que la LOPJ/1985 atribuyó al Congreso y al Senado. Comienza constatando las dificultades interpretativas atendiendo a la literalidad del artículo 122, apartados 2 y 3, de la CE - F.J. $12^{\text {o }}{ }^{26}$, y atendiendo a su íter parlamentario - F.J. $13^{\circ}{ }^{27}$. Y tras constatar esas dificultades interpretativas, el Tribunal Constitucional concluye que las hay porque no se quiso establecer quién o quiénes designarían a los vocales judiciales, ratificando esa conclusión desde la perspectiva del espíritu y finalidad de la norma constitucional -F.J. $13^{\circ}{ }_{-}^{28}$. Cierra la STC 108/1986 el tema de la constitucionalidad de

\footnotetext{
${ }^{24} \mathrm{Al}$ efecto de acreditar esta aseveración, según la STC 108/1986, "basta la simple lectura del texto constitucional, en el que, como se ha dicho, lo que se consagra es la independencia de cada Juez a la hora de impartir justicia, sin que la calidad de integrantes o miembros del Poder Judicial que se les atribuye en preceptos ya citados tenga otro alcance que el de señalar que solo los Jueces, individualmente o agrupados en órganos colegiados, pueden ejercer jurisdicción juzgando y haciendo ejecutar lo juzgado".

${ }^{25} \mathrm{Al}$ efecto de acreditar esta aseveración, la STC 108/1986 dice que "(la CE) ha querido crear un órgano autónomo que desempeñe determinadas funciones, cuya asunción por el Gobierno podría enturbiar la imagen de la independencia judicial, pero sin que de ello se derive que ese órgano sea expresión del autogobierno de los Jueces. La Constitución obliga, ciertamente, a que doce de sus vocales sean elegidos entre Jueces y Magistrados de todas las categorías, mas esta condición tiene como principal finalidad que un número mayoritario de vocales del Consejo tengan criterio propio por experiencia directa sobre los problemas que los titulares de los órganos judiciales afrontan en su quehacer diario, de la misma forma que, al asignar los restantes ocho puestos a Abogados y otros juristas de reconocida competencia con más de quince años de ejercicio en su profesión, se busca que aporten su experiencia personas conocedoras del funcionamiento de la justicia desde otros puntos de vista distintos del de quienes la administran".

${ }^{26}$ La STC 108/1986 reconoce que, "si se acude, en primer término, al texto mismo del artículo debatido, resulta que su examen no ofrece apoyo suficiente para una respuesta categórica al problema planteado".

${ }^{27}$ Que la STC 108/1986 explica en los siguientes términos: "El Anteproyecto de Constitución decía de modo explícito que 12 de los miembros del Consejo serán nombrados a propuesta y en representación de las distintas categorías de las carreras judiciales. La ponencia, por mayoría de los representantes de los Grupos de UCD y AP y sobre la base del texto contenido en un voto particular de la UCD y de otras enmiendas, dio una nueva redacción al texto estableciendo que, de 15 vocales que entonces se preveían para el Consejo, 10 serían propuestos entre Jueces y Magistrados en los términos que establezca la ley orgánica, y los otros 5 por el Congreso de los Diputados. En el debate en la Comisión se formuló por el representante del Grupo Parlamentario Socialista una enmienda in voce, en la que se proponía aumentar a veinte el número de vocales, 12 entre Jueces o Magistrados de todas las categorías y 8 por el Parlamento, enmienda que fue aceptada. Ciertamente, el representante del Grupo Socialista dijo en su intervención que con su enmienda iba a abrirse el colegio electoral, esta es al menos la interpretación de los socialistas, a todos los miembros, Jueces y Magistrados; pero en el debate que siguió a la propuesta, a la que se adhirieron otros Grupos Parlamentarios, no consta que el consentimiento de la Comisión recayese sobre la interpretación dada por el portavoz del Grupo Socialista al nuevo texto, sino sobre la ampliación del número de vocales a 20 y su extensión a todas las categorías judiciales. Tanto es así que, en el Senado, el texto aprobado por la Comisión (y sin debate por el Pleno del Congreso) fue objeto de una enmienda (la número 71 de progresistas y socialistas independientes) en que se proponía la atribución expresa de la propuesta de los 12 vocales a los Jueces y Magistrados mediante elección de todos los miembros de la carrera judicial, enmienda que no fue acogida". La STC 108/1986 a continuación reconoce que "verdad es que del tono de los debates constitucionales e incluso de los que tuvieron lugar con motivo de otras proyectos de Ley y de la insistencia en tales debates en que los Jueces y Magistrados elegibles lo sean de todas las categorías de la Carrera Judicial, según el texto finalmente aceptado, parece deducirse la existencia de un consenso implícito sobre la necesidad de que los 12 vocales procedentes de la Carrera Judicial expresasen no diferentes niveles de experiencia por su función y su edad, sino las distintas corrientes de pensamiento existentes en aquella", pero acaba concluyendo que "no se constitucionalizó una fórmula concreta, sino que los constituyentes se limitaron a remitirla a una futura ley orgánica".

${ }^{28}$ Según la STC 108/1986, "el fin perseguido es, de una parte, el de asegurar la presencia en el Consejo de las principales actitudes y corrientes de opinión existentes en el conjunto de Jueces y Magistrados en cuanto tales, es decir, con independencia de cuales sean sus preferencias políticas como ciudadanos y, de
} 
la parlamentarización de los vocales del CGPJ con unas palabras que han pasado a la historia constitucional española: "Ciertamente, se corre el riesgo de frustrar la finalidad señalada de la norma constitucional si las Cámaras, a la hora de efectuar sus propuestas, olvidan el objetivo perseguido y, actuando con criterios admisibles en otros terrenos, pero no en este, atiendan a la división de fuerzas existente en su propio seno y distribuyen los puestos a cubrir entre los distintos partidos, en proporción a la fuerza parlamentaria de estos. La lógica del Estado de partidos empuja a actuaciones de este género, pero esa misma lógica obliga a mantener al margen de la lucha de partidos ciertos ámbitos de poder y entre ellos, y señaladamente, el Poder Judicial. La existencia y aun la probabilidad de ese riesgo, creado por un precepto que hace posible, aunque no necesaria, una actuación contraria al espíritu de la norma constitucional, parece aconsejar su sustitución, pero no es fundamento bastante para declarar su invalidez, ya que es doctrina constante de este Tribunal que la validez de la ley ha de ser preservada cuando su texto no impide una interpretación adecuada a la Constitución" -F.J. $13^{\circ}$-.

En suma, la cláusula de apertura constitucional en la forma de designación de los vocales judiciales, permitiendo su designación parlamentaria como la de los no judiciales, apunta a la constitucionalidad del autogobierno limitado y, en consecuencia, a la conclusión de que no establecía el autogobierno pleno en la Constitución. Aunque la decisión del TC no ha cerrado la polémica, ni sobre la recepción constitucional del autogobierno pleno, ni en especial sobre el sistema de elección de los vocales judiciales, en primer lugar, porque el TC avaló una interpretación que supuso un cambio radical frente a la anterior basada en el consenso constitucional implícito, con lo cual era difícil que ello se aceptara unánimemente sin cuestionar la propia doctrina constitucional, $\mathrm{y}$, en segundo lugar, por los términos en los cuales se argumentó la cuestión de la elección aludiendo a un "riesgo de politización", con lo cual se produjo el efecto de apagar fuego con gasolina pues precisamente el riesgo de politización era uno de los argumentos contrarios a la elección parlamentaria. La experiencia en las sucesivas designaciones parlamentarias de los vocales judiciales ha actualizado ese riesgo de politización.

\title{
VI. A MODO DE CONCLUSIÓN: EL CONSEJO GENERAL DEL PODER JUDICIAL COMO GARANTE INSTITUCIONAL DE LA INDEPENDENCIA DEL PODER JUDICIAL
}

\author{
El Consejo General del Poder Judicial instaurado en el artículo 122 de la \\ Constitución Española de 1978 se inscribe claramente en una tendencia del
}

\footnotetext{
la otra, equilibrar esta presencia con la de otros juristas que, a juicio de ambas Cámaras, puedan expresar la proyección en el mundo del Derecho de otras corrientes de pensamiento existentes en la sociedad. La finalidad de la norma sería así, cabría afirmar de manera resumida, la de asegurar que la composición del Consejo refleje el pluralismo existente en el seno de la sociedad y, muy en especial, en el seno del Poder Judicial. Que esta finalidad se alcanza más fácilmente atribuyendo a los propios Jueces y Magistrados la facultad de elegir a doce de los miembros del CGPJ es cosa que ofrece poca duda; pero ni cabe ignorar el riesgo, también expresado por algunos miembros de las Cortes que aprobaron la Constitución, de que el procedimiento electoral traspase al seno de la Carrera Judicial las divisiones ideológicas existentes en la sociedad (con lo que el efecto conseguido sería distinto del perseguido) ni, sobre todo, puede afirmarse que tal finalidad se vea absolutamente negada al adoptarse otro procedimiento y, en especial, el de atribuir también a las Cortes la facultad de propuesta de los miembros del Consejo procedentes del Cuerpo de Jueces y Magistrados, máxime cuando la Ley (la LOPJ/1985) adopta ciertas cautelas, como es la de exigir una mayoría cualificada de tres quintos en cada Cámara (artículo 112.3 de la LOPJ de 1985)".
} 
constitucionalismo moderno dirigida, en especial en sistemas de carrera judicial en que, como en el español, la experiencia histórica se caracterizó por la ausencia de una auténtica independencia judicial dada la subordinación del Judicial al Poder Ejecutivo, a introducir una garantía institucional de la independencia judicial corporeizada en consejos de la magistratura que, a la vez que garantizan en sí mismos la independencia judicial institucional de la magistratura, garantizan tendencialmente mejor la independencia judicial de los jueces individuales al detraer la gestión del estatuto judicial de las manos del Poder Ejecutivo. La preocupación constitucional por la independencia judicial que lleva a tildar a la Justicia como Poder Judicial, la colocación sistemática del artículo 122 de la $\mathrm{CE}$, y su propia literalidad, donde se contempla un órgano judicial con una composición con mayoría de miembros togados, y donde se contempla la gestión del estatuto judicial como un contenido competencial mínimo, demuestran a las claras que la CE ha querido configurar al CGPJ como una garantía institucional de la independencia judicial a semejanza de la de Italia, Francia o Portugal.

De este modo, el CGPJ instaurado en la CE es una garantía institucional de la independencia del Poder Judicial, pues cumple las exigencias mínimas para ser ello así. Ahora bien, esas exigencias mínimas pueden ser ampliadas hasta un máximo que nos situaría en la elección directa de vocales judiciales y en un autogobierno pleno. Pero la CE no exige ese máximo. Será el legislador el que concretará, según las aspiraciones de independencia judicial que en cada momento histórico manifieste la sociedad a través de su representación política, si nos situamos tendencialmente hacia ese máximo o si nos sujetamos al mínimo, existiendo muchos puntos intermedios. Y no necesariamente una cosa es mejor o peor, pues lo relevante es que, respetando siempre el mínimo exigido constitucionalmente para la configuración como garantía institucional, exista esa adecuación entre norma y sociedad en cada momento histórico concreto, y que lo que aparece reflejado en la norma sea efectivamente cumplido en la realidad de las cosas, pues de nada sirven unas normas de gran alcance si luego no se cumplen, resultando mejor otras de menor alcance pero efectivamente cumplidas. Solo con esa adecuación entre la norma y las aspiraciones de la sociedad y con el efectivo cumplimiento de las normas, se sientan las bases sólidas para profundizar más en la independencia judicial.

\section{BIBLIOGRAFÍA}

AA.VV., El Poder Judicial y su Consejo en el Estado social y democrático de Derecho, CGPJ, Madrid, 1986.

ALBACAR LOPEZ, J.L. "Naturaleza jurídica del Consejo General del Poder Judicial", en AAVV, Jornadas de estudio sobre el Consejo General del Poder Judicial, CGPJ, Madrid, 1983.

ALMAGRO NOSETE, J., "Poder Judicial y Tribunal de Garantías en la nueva Constitución", en AAVV Lecturas sobre la Constitución Española, UNED, Madrid, 1978.

ANDRES IBÁÑEZ, P., MOVILlA ÁlvarEZ, C., "El Poder Judicial”, Teoría y realidad constitucional, $\mathrm{n}^{\circ}$. 8-9, 2001-2002.

BALleSter CARDELL, M., El Consejo General del Poder Judicial. Su función constitucional y legal, CGPJ, Madrid, 2007. 
DIEZ-PICAZO GIMÉNEZ, L., Régimen constitucional del Poder Judicial, Civitas, Madrid, 1991.

FERNÁNDEZ-MIRANDA CAMPOAMOR, C., "El Consejo General del Poder Judicial. De la Ley Orgánica 1/1980, de 10 de enero, a la Ley Orgánica 6/1985, de 29 de julio", Revista de Derecho Político, número 38, 1993.

LEDESMA BARTRET, F., "Relaciones entre el Consejo General y el Poder Ejecutivo", en AAVV, Jornadas de estudio sobre el Consejo General del Poder Judicial, CGPJ, Madrid, 1983.

MARTÍNEZ ALARCÓN, M.L., La independencia judicial, Centro de Estudios Políticos y Constitucionales, Madrid, 2004.

MURILLO DE LA CUEVA, P.L., "La posición constitucional del Consejo General del Poder Judicial y sus relaciones con los órganos constitucionales", en AAVV, EI Gobierno del Poder Judicial en el Estado autonómico: Evolución y perspectivas de reforma", Marcial Pons, Madrid, 2013.

REQUERO IBÁÑEZ, J.L., El Gobierno Judicial y el Consejo General del Poder Judicial, Fundación para el análisis y los estudios sociales, Papeles de la Fundación, Madrid, 1996.

SANCHEZ BARRIOS, M.I., La elección de los miembros del Consejo General del Poder Judicial español y de sus homólogos europeos, Tirant lo Blanch, Valencia, 2009.

SANCHEZ BARRIOS, M.I., “Antecedentes del CGPJ en el Derecho español”, Poder Judicial, número 46, 1997.

TEROL BECERRA, M., "Veinticinco años del Consejo General del Poder Judicial", Revista Derecho Político, números 58/59, 2003/4. 